\title{
Medial Geniculate, Amygdalar and Cingulate Cortical Training- Induced Neuronal Activity during Discriminative Avoidance Learning in Rabbits with Auditory Cortical Lesions
}

\author{
Adam D. Duvel, ${ }^{1}$ David M. Smith, ${ }^{1}$ Andrew Talk, ${ }^{3}$ and Michael Gabriel ${ }^{1,2,3}$ \\ ${ }^{1}$ Neuroscience Program, ${ }^{2}$ Department of Psychology, and ${ }^{3}$ Beckman Institute, University of Illinois, Urbana, Illinois 61801
}

This study addressed the neural mediation of discriminative avoidance learning, wherein rabbits step in a wheel apparatus in response to an acoustic conditional stimulus, the CS+, to avoid a foot shock, and they learn to ignore a different stimulus, the CS-, not followed by foot shock. Previously, muscimolinduced inactivation of the amygdala in the first session of training prevented learning during the inactivation and permanently blocked the development of discriminative traininginduced neuronal activity (TIA) in the medial division of the medial geniculate nucleus (MGm). These results suggested that amygdalar neurons induce discriminative TIA in the MGm via basolateral (BL) amygdalar axonal projections to the auditory cortex. To test this hypothesis, the activity of neurons in the MGm was recorded during learning in rabbits with lesions of the auditory cortex. Recordings were also made in the lateral and
$\mathrm{BL}$ amygdalar nuclei and in the cingulate cortex. In support of the hypothesis, discriminative learning in rabbits with lesions was impaired significantly during early training sessions 1-4; in these same sessions, discriminative TIA was abolished in the MGm, the BL nucleus, and the anterior cingulate cortex. The lesions also blocked posterior cingulate cortical discriminative TIA in training sessions 1-2 but spared TIA in sessions 3-7. Lateral amygdalar neurons showed gradual development of discrimination that was not significantly affected by the lesions. The results demonstrate a critical role of auditory cortex in early discriminative learning and in the production of early discriminative TIA in multiple areas.

Key words: lesions; rabbits; multisite neuronal activity; discriminative avoidance learning; medial geniculate nucleus; lateral amygdala; basolateral amygdala; cingulate cortex
It is well known that the amygdala and the medial geniculate nucleus of the thalamus are involved in aversively motivated, acoustically cued conditioning. Lesions in these areas impair learning in a variety of classical and instrumental conditioning tasks (Kapp et al., 1979; Gentile et al., 1986; Jarrell et al., 1986a,b; LeDoux et al., 1986, 1990; Hitchcock and Davis, 1987; McCabe et al., 1993; Fanselow and Kim, 1994; Poremba and Gabriel, $1997 \mathrm{a}, \mathrm{b})$, and the firing patterns of neurons in these areas undergo associative change during learning (Gabriel et al., 1975, 1976; Maren et al., 1991; Edeline and Weinberger, 1992; Lennartz and Weinberger, 1992; Muramoto et al., 1993; McEchron et al., 1995, 1996; Quirk et al., 1995).

Neurons in the medial division of the medial geniculate nucleus (MGm) send axonal projections to amygdalar and periamygdalar regions (LeDoux et al., 1985). Knowledge of this pathway has fostered the hypothesis that neurons of the MGm send primarily acoustic information to the amygdala, which then supports conditioning-related associative changes at amygdalar synapses (LeDoux, 1993, 1995; Maren and Fanselow, 1996). However, recent findings have suggested the opposite direction of influence. Amygdalar neurons support training-induced, associative changes in the firing patterns of neurons in the MGm during discriminative avoidance learning in rabbits. Muscimol-induced inactivation of the amygdala at the outset of training blocked learning as well as the development of discriminative training-induced neuronal

\footnotetext{
Received Oct. 3, 2000; revised Feb. 9, 2001; accepted Feb. 13, 2001.

This work was supported by National Institutes of Health Grant NS26736 to M.G. Correspondence should be addressed to Dr. Michael Gabriel, University of Illinois, Beckman Institute, 405 N. Mathews, Urbana, IL 61801. E-mail: mgabriel@s.psych.uiuc.edu.

Copyright (C) 2001 Society for Neuroscience $\quad 0270-6474 / 01 / 213271-11 \$ 15.00 / 0$
}

activity (TIA) in the MGm. The TIA consisted of significantly greater neuronal firing in response to the positive conditional stimulus, $\mathrm{CS}+$, than to the negative conditional stimulus, $\mathrm{CS}-$ (Poremba and Gabriel, 1999, 2001). During subsequent sessions with no muscimol present, the rabbits learned (but with moderate impairment), and discriminative TIA developed in other learning-relevant areas, including the cingulate cortex and related areas of the thalamus. However, no discriminative TIA developed in the MGm. These results indicated that early in training amygdalar processes are essential for the development of discriminative TIA in the MGm.

Direct axonal projections from the amygdala to the MGm have not been found; thus, it is of interest to inquire as to the route whereby amygdalar efferents influence neuronal activity of the MGm. Neurons of the basolateral (BL) nucleus of the amygdala send axons to the auditory cortex (Macchi et al., 1978; Amaral and Price, 1984; Sripanidkulchai et al., 1984), and auditory cortical neurons send massive corticothalamic projections to the MG nucleus (Diamond et al., 1969; Pontes et al., 1975, Andersen et al., 1980; DeVenecia et al., 1998). These projections could relay the amygdalar neuronal activity that is involved in the induction of TIA in the MGm.

The present study tested this hypothesis by recording neuronal activity in the MGm during learning in rabbits with auditory cortical lesions. The activity of the BL amygdala and cingulate cortex was recorded also, because these areas exhibit robust TIA and are importantly involved in discriminative avoidance learning. Finally, several studies have demonstrated learning-related alterations of neurons of the lateral (LA) nucleus of the amygdala during aversively motivated Pavlovian conditioning (Ben-Ari and Le Gal La Salle, 1974; Quirk et al., 1995; Hennevin et al., 1998; 
Maren, 2000; Collins and Paré, 2000; Paré and Collins, 2000). Here, for the first time, we show similar changes in relation to discriminative avoidance learning of rabbits.

\section{MATERIALS AND METHODS}

Subjects. The subjects were 35 male New Zealand White rabbits weighing $1.5-2.0 \mathrm{~kg}$ on delivery to the laboratory and maintained on ad libitum water and one cup of rabbit chow daily. The mild restriction of food intake has been found to prevent obesity.

Surgical implantation of recording electrodes. After a minimum of $7 \mathrm{~d}$ for adaptation to the living cages, each rabbit underwent surgery for lesion induction and implantation of recording electrodes. Surgical anesthesia was induced by subcutaneous injection $(1 \mathrm{ml} / \mathrm{kg})$ of a solution containing $60 \mathrm{mg} / \mathrm{ml}$ ketamine $\mathrm{HCl}$ and $8 \mathrm{mg} / \mathrm{ml}$ xylazine, followed by hourly injections of $1 \mathrm{ml}$ of the solution. Each rabbit was placed in a Kopf stereotaxic head restraint. Six recording electrodes were implanted through burr holes (diameter, $0.5 \mathrm{~mm}$ ) drilled through the skull over the target sites. The electrodes were made from stainless steel pins (catalog \#00; uninsulated shaft diameter, $0.28-0.30 \mathrm{~mm}$ ) insulated with Epoxylite. The recording surfaces were made by removing insulation from the tips of the pins. The recording surfaces ranged from 10 to $40 \mu \mathrm{m}$ from tip to insulation and had impedances from 0.5 to $2.0 \mathrm{M} \Omega$.

Electrode guides made of Teflon (length, $2.5 \mathrm{~mm}$; diameter, $1.5 \mathrm{~mm}$ ) were impaled on uninsulated pins that were positioned over each burr hole and affixed to the skull using dental acrylic. The pins were removed after hardening of the dental acrylic. The recording electrodes were advanced slowly to the target by press-fitting them through the pinholes in the Teflon guides. The guides held the electrodes firmly during advancement, while avoiding rigid attachment of the electrodes to the stereotaxic manipulator, thus minimizing the risk that small movements of the rabbit (e.g., caused by respiration) would disrupt the recordings. Wires were presoldered to the electrodes and to each of six contact pins in a nine-pin connector that also was affixed to the skull with dental acrylic and machine screws. An additional stainless steel machine screw threaded into the frontal sinus served as the reference electrode.

Neuronal activity was monitored acoustically and with an oscilloscope during electrode advancement to facilitate accurate placement of the electrodes. Stereotaxic coordinates (Girgis and Shih-Chang, 1981) for electrode placements in these studies were as follows: the MGm, anteroposterior (AP), $+7.5 \mathrm{~mm}$; mediolateral $(\mathrm{ML}), \pm 5.0 \mathrm{~mm}$; and dorsoventral (DV), $10-12 \mathrm{~mm}$; the BL nucleus of the amygdala, AP, $-0.5 \mathrm{~mm}$; ML, $\pm 6.0 \mathrm{~mm}$; and DV, $11-13 \mathrm{~mm}$; the LA nucleus of the amygdala, AP, $0.0 \mathrm{~mm}$; ML, $\pm 6.5 \mathrm{~mm}$; DV, $10-12 \mathrm{~mm}$; the anterior cingulate cortex (Brodmann's area 24b), AP, $-3.5 \mathrm{~mm}$; ML, $\pm 0.5 \mathrm{~mm}$; DV, $2-4 \mathrm{~mm}$; and the posterior cingulate cortex (Brodmann's areas 29c and 29d), AP, +4.0 $\mathrm{mm}$; ML, $\pm 0.5 \mathrm{~mm}$; and DV, $1-4 \mathrm{~mm}$.

Lesions. Bilateral electrolytic lesions of the auditory cortex were induced during surgery using electrodes made from stainless steel insect pins insulated with Epoxylite. The insulation was removed from the tips to uncover $0.80-0.90 \mathrm{~mm}$ of the metal. An electrode was positioned at the target sites under stereotaxic guidance, and a $1.5 \mathrm{~mA}$ cathodal DC current was passed for $30 \mathrm{sec}$. The target sites (10 per hemisphere) were as follows: AP,$+1.0 \mathrm{~mm}$; ML, $\pm 11.0 \mathrm{~mm}$; DV,-4.0 and $-6.0 \mathrm{~mm}$; AP, $+3.0 \mathrm{~mm}$; ML, $\pm 1.0 \mathrm{~mm}$; DV $,-4.0,-6.0$, and $-8.0 \mathrm{~mm}$; AP, $+5.0 \mathrm{~mm}$; $\mathrm{ML}, \pm 11.0 \mathrm{~mm}$; DV $,-4.0,-6.0$, and $-8.0 \mathrm{~mm}$; and AP, $+7.0 \mathrm{~mm}$; ML, $\pm 11.0 \mathrm{~mm} ; \mathrm{DV},-4.0$ and $-6.0 \mathrm{~mm}$.

Collection of neuronal data. During discriminative avoidance training, the neuronal records were fed into field-effect transistors (FETs) that served as high-impedance source followers. The FETs were attached to a connector that mated with the nine-pin connector that was affixed to the skull. The FET outputs were fed via individually shielded cables into single-ended preamplifiers having a bandwidth appropriate for single unit recording (gain, 8000; one-half amplitude cutoffs at 500 and 8000 $\mathrm{Hz}$ ). The neuronal activity was subjected to a second stage of active bandpass filtering (one-half amplitude cutoffs at 600 and $8000 \mathrm{~Hz}$; roll-off, $18 \mathrm{~dB} /$ octave) to remove all slow EEG frequencies. Then the filter outputs were fed into discriminators that produced an $80 \mu \mathrm{sec}$ square-wave output pulse when the input voltage fell within a preset window. Triggering thresholds were adjusted automatically under computer control to yield a mean pulse rate of 95-165 pulses per second. Using this criterion, the combined frequency of firing of the largest action potentials typically was sampled. The criterion was established by past usage to limit the number of sampled neurons while nevertheless yielding robust and repeatable multiunit discharge profiles.
In addition to the sampling of action potential firing frequency, the bandpass filter outputs were half-wave rectified and integrated to yield a measure of integrated unit activity (Buchwald et al., 1973). The time constants for the rise and fall of the integrators were $15 \mathrm{msec}$. The integrated activity samples were more inclusive than the spike frequency samples. They assessed the firing of all neurons in the range of the recording electrode, including activity below the triggering threshold used for spike frequency sampling.

The integrated activity and firing frequency measures are complementary. The temporal profiles yielded by the integrated activity measure have lower fidelity than those yielded by the firing frequency, because of the smoothing effect of the time constants. However, the integration process reduces variability and thus increases the sensitivity of the integrated activity, allowing detection of effects occasionally missed by the firing frequency measure.

Firing frequency, as indicated by the discriminator outputs, was counted, and the integrator outputs were digitized in $100,10 \mathrm{msec}$ recording intervals, or "bins," 30 intervals $(300 \mathrm{msec})$ before tone onset and 70 intervals after CS onset. A digital value was stored for each electrode at each $10 \mathrm{msec}$ interval. We computed Z-scores that measured the magnitude of the neuronal response in each post-CS interval normalized with respect to the pre-CS baseline activity. To compute the $\mathrm{Z}$-scores, we subtracted the mean activity scores in the 30 pre-CS baseline intervals from the activity scores in each of 70 post-CS intervals. The differences were divided by the SD of the pre-CS intervals.

The rabbits remained essentially motionless on a large majority of the conditioning trials throughout the $1 \mathrm{sec}$ sampling interval, which consisted of the $300 \mathrm{msec}$ baseline period (before CS onset) and the 700 msec period after CS onset. Occasionally, however, spontaneous locomotion, chewing, sneezing, and grooming occurred during the $1 \mathrm{sec}$ sampling interval, and on rare occasions locomotory conditioned responses (CRs) occurred at brief latencies such that CR-related movement artifacts occurred during the final $200 \mathrm{msec}$ of the sampling interval. Data samples accompanied by movement and movement-related artifact were discarded using a variety of automatic and experimenterinitiated screening procedures (Gabriel et al., 1983). In addition, the analyses were restricted to the first $40,10 \mathrm{msec}$ intervals after CS onset, because movement artifacts related to initiation of the locomotory CR do not occur in these early intervals.

Avoidance training. All rabbits recovered from surgery for 7-14 d before discriminative avoidance training was initiated. Training was administered while the rabbit occupied a large activity wheel designed for the conditioning of small animals (Brogden and Culler, 1936). The wheel was housed in a shielded chamber with an exhaust fan and a speaker that produced a masking noise $\left(70 \mathrm{~dB}\right.$ re: $\left.20 \mathrm{~N} / \mathrm{m}^{2}\right)$ throughout training. The $\mathrm{CS}+$ and $\mathrm{CS}-$ were pure tones $(0.5 \mathrm{sec}$ duration, 1 or 8 $\mathrm{kHz}$, at $85 \mathrm{~dB}$ re: $20 \mathrm{~N} / \mathrm{m}^{2}$; rise time, $3 \mathrm{msec}$ ) played through a loudspeaker attached to the chamber ceiling directly above the rotator. Assignment of tones as $\mathrm{CS}+$ or $\mathrm{CS}-$ was counterbalanced.

During avoidance training, the onset of the CS+ was followed after 5 sec by the foot shock unconditional stimulus (US; a constant current of 1.5-2.5 mA delivered through the grid floor of the rotator). The minimal shock intensity needed to elicit a consistent locomotory response was established during the first few trials of pretraining with unpaired CS and US presentations (see below). This procedure, which resulted in individualized settings of the shock intensity, promoted learning in virtually all subjects and decreased variability between subjects.

Behavioral responses were defined as locomotion-induced rotations of $\geq 2^{\circ}$. The US was terminated by locomotor responses to the foot shock. The maximum duration of the US was $1 \mathrm{sec}$. Behavioral responses performed during the interval from $\mathrm{CS}+$ onset to US onset prevented the occurrence of the US. Such responses were defined as conditioned avoidance responses or CRs. The negative conditional stimulus $(\mathrm{CS}-)$ was never followed by the US. Both the CS + and $\mathrm{CS}-$ were presented 60 times in each training session in an irregular sequence. The episodes consisting of the presentation of the CS and US and any related behavioral responding are referred to as trials. The interval from the end of a given trial to the onset of the ensuing trial was $8,13,18$, or $23 \mathrm{sec}$. These values occurred in an irregular sequence. Responses during the intertrial interval reset the interval. Although a minimal wheel turn of $2^{\circ}$ was scored as a response, the learned avoidance responses of the rabbits were invariably of a much greater magnitude, consisting of one or more steps in the wheel. The average magnitude of the avoidance response of trained rabbits is $\sim 200^{\circ}$ of wheel rotation. 

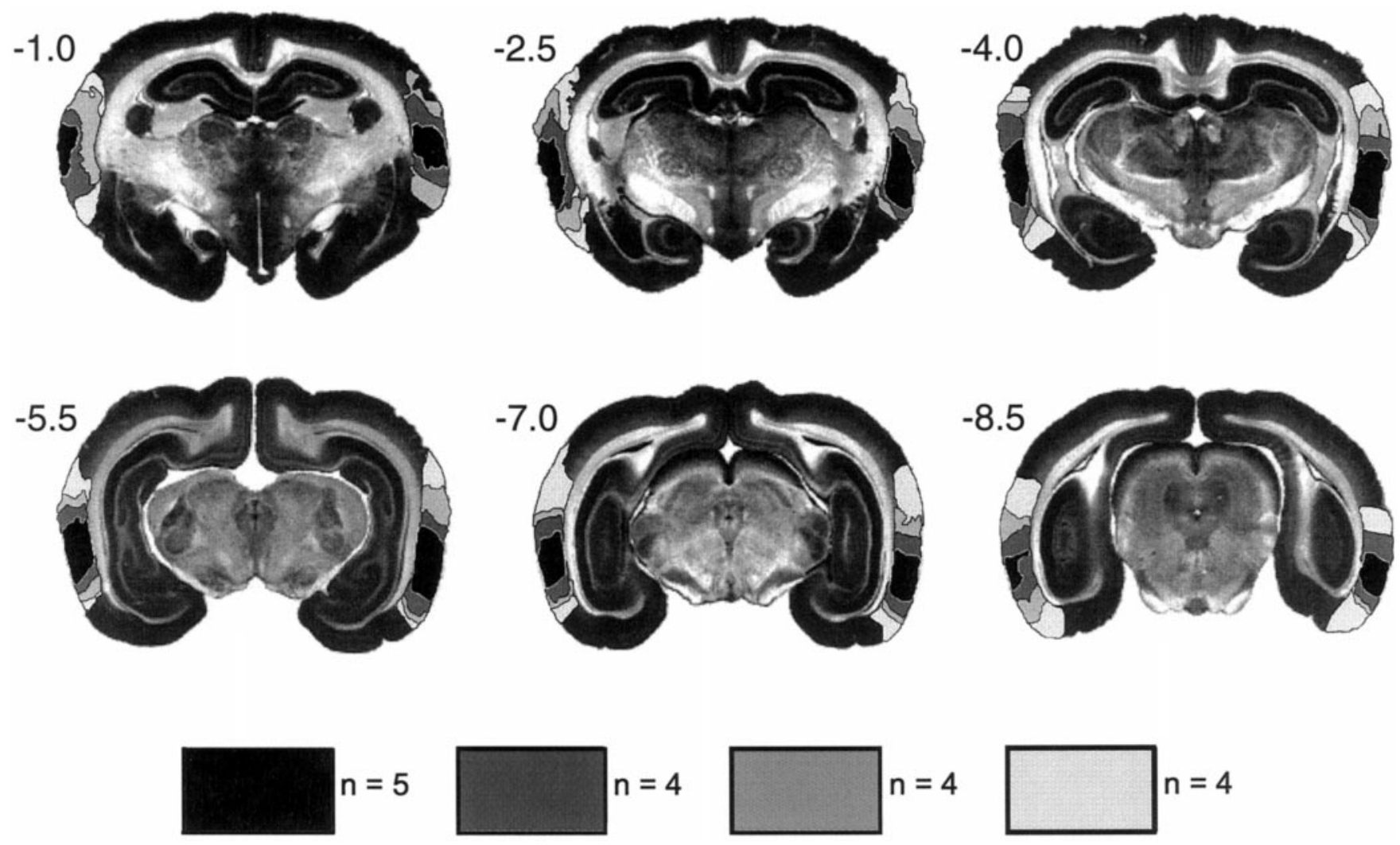

Figure 1. The auditory cortical lesions are represented on coronal sections at the indicated levels posterior to bregma. Four different lesion magnitudes were defined on the basis of the proportion of pixels exhibiting lesion (see Results). Also given is the number of subjects with lesions in each magnitude category.

Each rabbit received two pretraining sessions before beginning discriminative avoidance training. In the first pretraining session, 60 presentations of each tone were given without the US, but with the same timing and ordering as during training. In the second pretraining session, rabbits received the same schedule of tone presentations as during the initial pretraining session, but in addition, US presentations were given in an explicitly unpaired manner (Rescorla, 1967). That is, the US was not presented during a tone or within $3 \mathrm{sec}$ before or after a tone presentation. The schedule of US presentations was designed to mimic the schedule of US presentations during the first session of avoidance conditioning. That is, the number and trial distribution of US presentations was based on average values of these parameters observed during the first session of conditioning in a sample of 100 rabbits. The pretraining with shock (PTS) session provided baseline data for detecting associative neuronal and behavioral changes induced during the first conditioning session in which the CS was explicitly paired with the US.

Discriminative avoidance training was initiated $24 \mathrm{hr}$ after the PTS session. All animals received one session of discriminative avoidance training each day. Sessions of training consisted of 120 trials, 60 with the $\mathrm{CS}+$ and 60 with the CS-. Daily training sessions were given until the subjects reached a behavioral criterion that required performance in two consecutive sessions of CRs on $60 \%$ more CS + than CS - trials. After criterion attainment, the rabbits received five sessions of postcriterial overtraining.

Analysis of data. The neuronal data in the form of Z-scores (described above) were submitted to factorial, repeated measures ANOVA using the $2 \mathrm{~V}$ program (BMDP Statistical Software). The $\alpha$ level for all testing was set at 0.05. The analyses had orthogonal factors of lesion (two levels, lesion and control), session (eight levels, pretraining with shock and seven consecutive sessions of discriminative avoidance training and overtraining), stimulus (two levels, CS + and $\mathrm{CS}-$ ) and, for the neuronal data, recording interval (40 consecutive $10 \mathrm{msec}$ post-CS recording intervals). Correction of the $\mathrm{F}$ test because of disconformity of the data with the sphericity assumption of these analyses was performed using the procedure of Hyunh and Feldt (1976). Factors yielding significant overall $\mathrm{F}$ ratios were analyzed further using simple effect tests following Winer (1962).

Histology. Euthanasia was administered via an overdose of sodium pentobarbital followed by transcardial perfusion with normal saline and $10 \%$ formalin. Brains were frozen and sectioned at $40 \mu \mathrm{m}$. Sections containing the electrode tracks or lesions were placed on slides and photographed while still wet (Fox and Eichman, 1959). The sections were subjected to Nissl and formol-thionin staining (Donovick, 1974).

Lesions and the experimental groups. Determination of the boundaries of auditory cortical areas in the rabbit was based on the work of McMullen and DeVenecia (McMullen and DeVenecia, 1993; McMullen et al., 1994; DeVenecia et al., 1998). The areas assessed were the primary and secondary auditory cortex, the anterior auditory field, and the posterior auditory field. The number of rabbits in the lesion and control groups were 17 and 18, respectively. The areas of auditory cortex were drawn onto high-resolution digital images of coronal sections through auditory cortex using a recently constructed digital rabbit brain atlas (Payne et al., 1999). The total number of pixels in each area was calculated using Adobe Photoshop v5.0.2. The lesion of each rabbit was drawn then as a semitransparent layer on top of the brain sections. The number of pixels encompassed by the lesion in each cortical area was divided by the total number of pixels in the area to determine the percentage of damage. The mean percentage of damage summed for all cortical areas was $72.62 \%$, with means of $87.44 \%$ in the primary auditory cortex, $40.71 \%$ in the secondary auditory cortex, $10.24 \%$ in the anterior auditory field, and $25.34 \%$ in the posterior auditory field. One rabbit was excluded from the study because it had $<50 \%$ damage to primary auditory cortex. An overlay depicting the various lesion magnitudes is shown in Figure 1.

Distribution of neuronal records. A total of 92 neuronal records were obtained in the designated recording sites. The numbers of records per area in lesion and control rabbits were, respectively: MGm, 14 and 10; BL amygdala, 9 and 7; LA amygdala, 6 and 6; anterior cingulate cortex, 12 and 9; posterior cingulate cortex, 11 and 8 . 


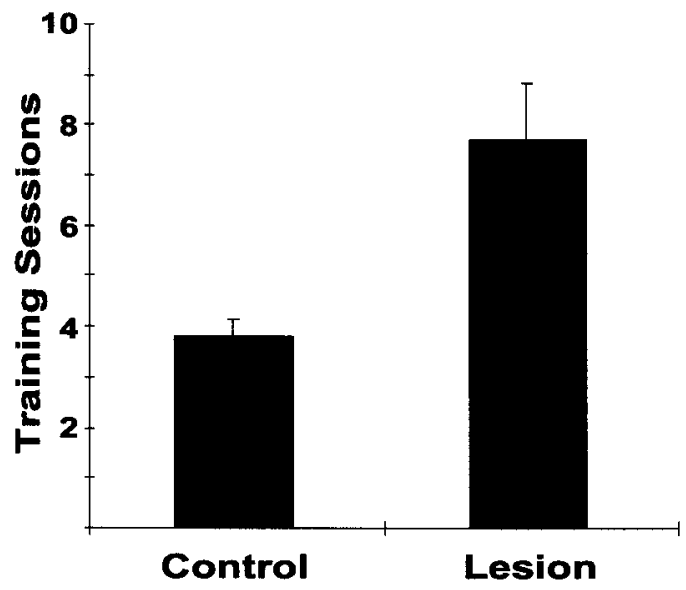

Figure 2. Number of training sessions administered to rabbits with lesions and controls before the exhibition of criterial performance, as defined in Materials and Methods. Error bars represent the SEM.

\section{RESULTS}

\section{Discriminative avoidance learning and performance Overview}

Preliminary analyses indicated that the effects of the lesions on behavioral learning and on neuronal activity occurred only during training to criterion. All but two subjects attained criterion during the first seven sessions of training. The two subjects that did not attain criterion had lesions. These subjects did not attain criterion within 15 sessions of training, the maximum number of sessions administered before declaring failure to learn. Nevertheless, they did acquire significant discriminative behavior during the first seven training sessions. Therefore, the behavioral and neuronal data reported below were the data of all subjects, including the two that did not attain the criterion. Data of the pretraining session (PTS, involving tone and unpaired foot shock presentations) and the first seven sessions of training were analyzed.

The lesions did not block learning. They did, however, produce a specific learning impairment, a significant deficit of behavioral discrimination in the first four training sessions. During the first session of training, rabbits with lesions failed to show any discriminative responding, i.e., a significantly greater frequency of avoidance responses to the $\mathrm{CS}+$ than to the $\mathrm{CS}-$, whereas controls discriminated significantly. During sessions $2-5$, the rabbits with lesions made significantly fewer avoidance CRs to the $\mathrm{CS}+$ than controls, and they made significantly more CRs to the
CS - than controls. The performance of rabbits with lesions did not differ from that of controls during training sessions 6 and 7 .

\section{Lesions and learning rate}

Auditory cortical lesions were associated with significantly retarded learning, as shown by an increase in the number of sessions required for attainment of the learning criterion in rabbits with lesions (Fig. 2). The average numbers of training sessions were 7.71 and 3.82 , respectively, for rabbits with lesions and controls. This difference yielded a significant main effect of the lesion factor $\left(p<0.002 ; F_{(1,34)}=9.87\right)$. The two rabbits with lesions that failed to reach the criterion received a score of 15 (the maximum number of daily training sessions administered before learning failure was declared).

\section{Lesions and CR performance during training}

Auditory cortical lesions were associated with a reduced frequency of $\mathrm{CR}$ performance in response to the $\mathrm{CS}+$ and an increased frequency of CRs to the CS- during early sessions of training. This pattern of results was indicated by a significant interaction of the session, stimulus, and lesion factors $(p<$ $\left.0.0001 ; F_{(7,231)}=8.18\right)$. Simple effect tests demonstrated discriminative behavior in controls (significantly more frequent CRs in response to the $\mathrm{CS}+$ than to the $\mathrm{CS}-$ ). However, significant discrimination in the rabbits with lesions did not occur during the first session of training. The rabbits with lesions showed significant behavioral discrimination in the remaining sessions (2-7), as did controls. However, rabbits with lesions made significantly fewer responses to the $\mathrm{CS}+$ than controls during the second and third sessions of training and significantly more responses to the CS - than controls during the second, third, fourth, and fifth training sessions (Fig. 3).

The fact that the learning deficit consisted of decreased responding to the $\mathrm{CS}+$ and increased responding to the $\mathrm{CS}-$ indicated that it was specifically a loss of discrimination, not an inability to acquire and perform the CR. No significant differences between rabbits with lesions and controls were found in overall response rate, the mean latency and duration of avoidance CRs, the mean latency and duration of escape responses to the foot shock US, and the mean number of inter-trial responses.

\section{Neuronal activity \\ Brief overview}

The general finding of this study was that just as in the case of behavioral discrimination, training-induced discriminative neuronal activity, which was clearly present in controls, was absent in the initial 2-4 sessions of training in rabbits with lesions in all of

Figure 3. Percentage of conditioned responses to the $\mathrm{CS}+$ (black bars) and CS- (white bars) during the pretraining with shock $(P T S)$ session and the first seven sessions of training in control rabbits $(n=18)$ and rabbits with lesions of the auditory cortex $(n=17)$. Significant differences between groups $(p<0.05)$ are indicated with an asterisk.
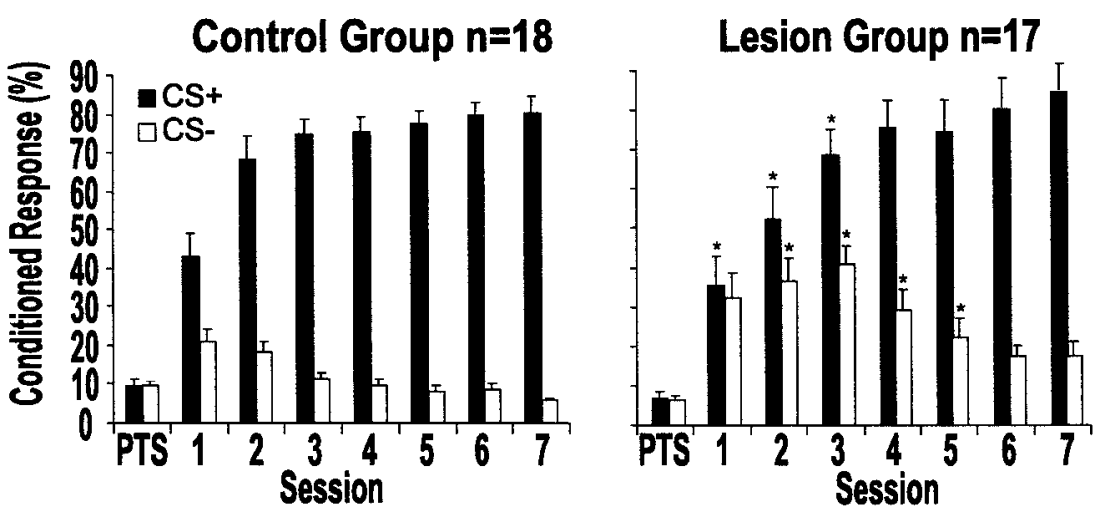

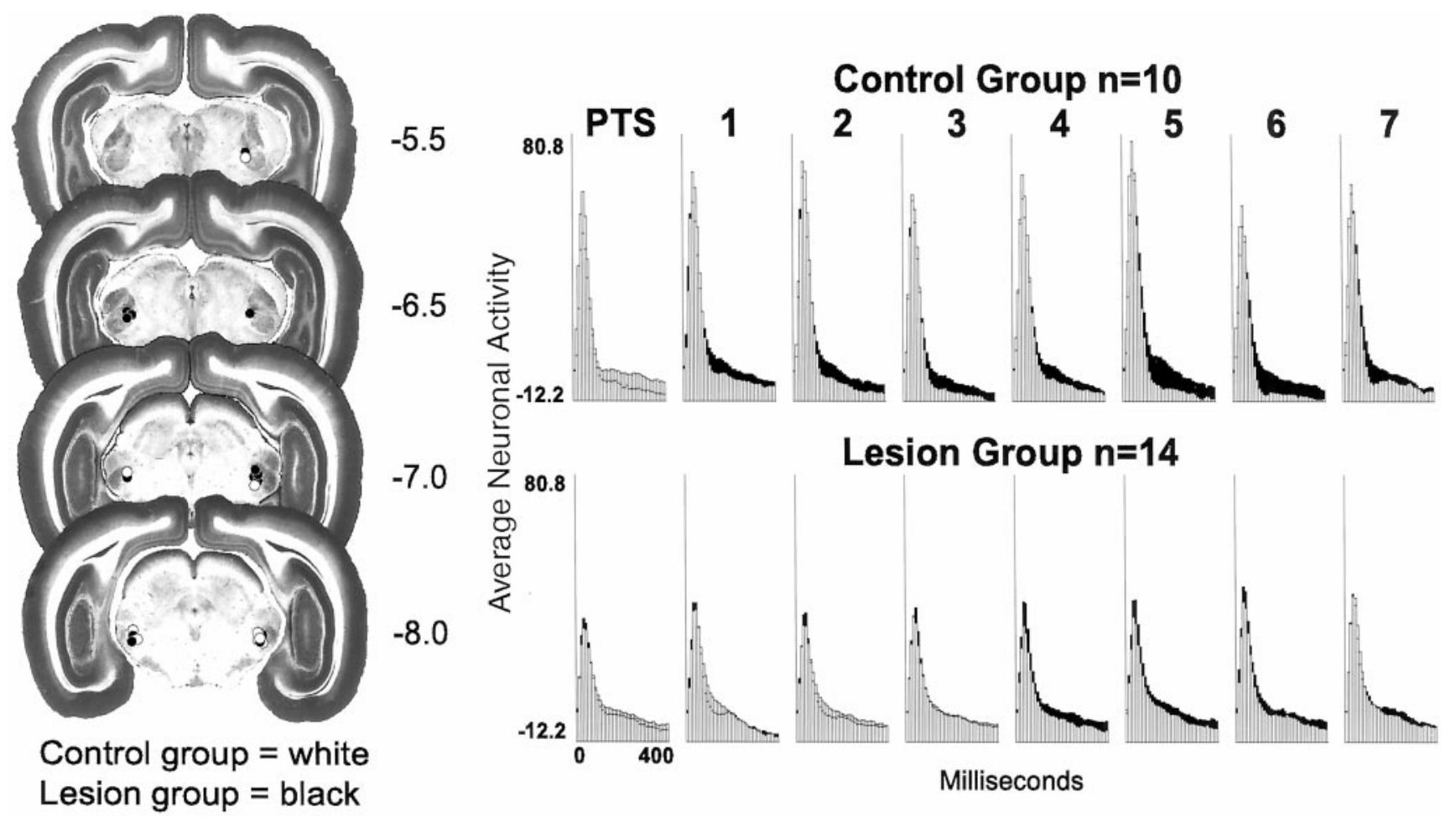

Figure 4. Electrode placements and neuronal activity recorded from the medial division of the MGm during pretraining with tone and unpaired foot shock presentations $(P T S)$ and during the first seven consecutive sessions of training in the control group $(n=10)$ and the lesion group $(n=14)$. Plotted are neuronal responses to the CS+ (black) and CS- (white) in 40 consecutive $10 \mathrm{msec}$ intervals after tone onset.

the monitored areas except the LA amygdalar nucleus. Neurons in the MGm, BL amygdalar nucleus, and anterior cingulate cortex showed little or no TIA development in later sessions of training, whereas the later development of TIA in the posterior cingulate cortex was robust.

\section{Absence of early discriminative TIA and severe attenuation of later TIA in the MGm, the basolateral nucleus of the amygdala, and the anterior cingulate cortex in rabbits with lesions of the auditory cortex}

Discriminative TIA in the MGm, which was present in controls, was eliminated in the rabbits with lesions (Fig. 4). This outcome was indicated by a significant four-way interaction of the session, stimulus, recording interval, and lesion factors in the analysis of the integrated neuronal activity $\left(p<0.05 ; F_{(273,6006)}=1.58\right)$. In control rabbits, simple effect tests showed significant discriminative TIA (greater neuronal firing in response to the CS+ than to the $\mathrm{CS}-$ ) at several poststimulus $10 \mathrm{msec}$ intervals for all training sessions except the pretraining session and training session 4 . The poststimulus intervals in which discriminative TIA was found are given in Table 1. No discriminative activity was found during pretraining or during training in the rabbits with lesions, with the exception of discrimination at three early intervals (from 31 to 60 msec after CS onset) in training sessions 4 and 5 (Table 1). It is unlikely that these differences represented bona fide discriminative TIA. Rather these differences likely reflected a nonassociative enhancement of a preexisting neuronal tone preference. This conclusion is based on the consistent presence of a numerically greater response to the $\mathrm{CS}+$ than to the $\mathrm{CS}-$ in these intervals during pretraining and the first three training sessions, the nearsignificance of the differences in these sessions, and the fact that discriminative TIA was not found in these intervals in the controls or in previous studies.
Although discriminative neuronal activity was not present in the firing frequency data in rabbits with lesions, whereas discrimination in controls was shown clearly in the plotted data, the analysis of the firing frequency data did not reveal a significant effect of the lesions. This negative outcome was likely attributable to increased variability of the firing frequency data, compared with the integrated activity, especially in the initial tone-related firing burst during the first $80 \mathrm{msec}$ after CS onset. To eliminate this variability, an analysis was performed on the firing frequency data in the interval from 100 to 200 msec after CS onset. In this analysis, the interaction of the CS and lesion factors approached significance $\left(p<0.08 ; F_{(1,22)}=3.57\right)$. The average spike frequency over all sessions, in response to the CS+ $(+2.73)$, significantly exceeded the response to the $\mathrm{CS}-(-2.98)$ in controls $(p<0.05)$, whereas the corresponding difference in rabbits with lesions (0.81 and 0.44$)$ was not significant. These results are in accord with the results of the analysis of the integrated activity in indicating that discriminative neuronal activity of the MGm was absent in the rabbits with lesions.

In addition to eliminating TIA development in the MGm, the auditory cortical lesions significantly diminished the response of MGm neurons irrespective of stimulus type. This was indicated by a significant interaction of the lesion and recording interval factors $\left(p<0.0001 ; F_{(39,663)}=13.02\right)$. Analysis of simple effects indicated that neurons in the controls exhibited a significantly greater response than neurons in rabbits with lesions from 21 to $90 \mathrm{msec}$ after the onset of the conditional stimuli during maximal stimulus-evoked firing of neurons in the MGm.

Elimination of early discriminative TIA in the BL nucleus (Fig. 5 ) in rabbits with lesions was indicated by significant interactions of the session, stimulus, and lesion factors $\left(p<0.04 ; F_{(7,98)}=\right.$ 2.45 , integrated activity; $p<0.05 ; \mathrm{F}_{(7,98)}=2.18$, firing frequen- 
Table 1. The $10 \mathrm{msec}$ intervals in which significantly greater MGm and lateral amygdalar neuronal responses occurred in response to the CS+ than to the CS- in the control and lesion groups

\begin{tabular}{|c|c|c|c|c|c|c|c|c|}
\hline & \multicolumn{8}{|l|}{ Sessions } \\
\hline & PTS & 1 & 2 & 3 & 4 & 5 & 6 & 7 \\
\hline \multicolumn{9}{|l|}{ MGm } \\
\hline Control group & 0 & $\begin{array}{c}21-30 \\
121-130\end{array}$ & $111-130$ & $111-120$ & & $81-250$ & $81-180$ & $81-150$ \\
\hline Lesion group & & & & & $31-60$ & $41-60$ & & \\
\hline \multicolumn{9}{|l|}{ Lateral amygdala } \\
\hline Combined lesion and control groups & $61-130$ & $\begin{array}{c}51-70 \\
91-320 \\
361-400\end{array}$ & $\begin{array}{l}110-120 \\
151-160 \\
180-190 \\
210-230 \\
261-270\end{array}$ & $\begin{array}{r}91-250 \\
271-400\end{array}$ & $71-400$ & $\begin{array}{r}71-280 \\
300-400\end{array}$ & $\begin{array}{r}41-210 \\
240-310\end{array}$ & $\begin{array}{c}61-70 \\
100-220 \\
251-290\end{array}$ \\
\hline
\end{tabular}
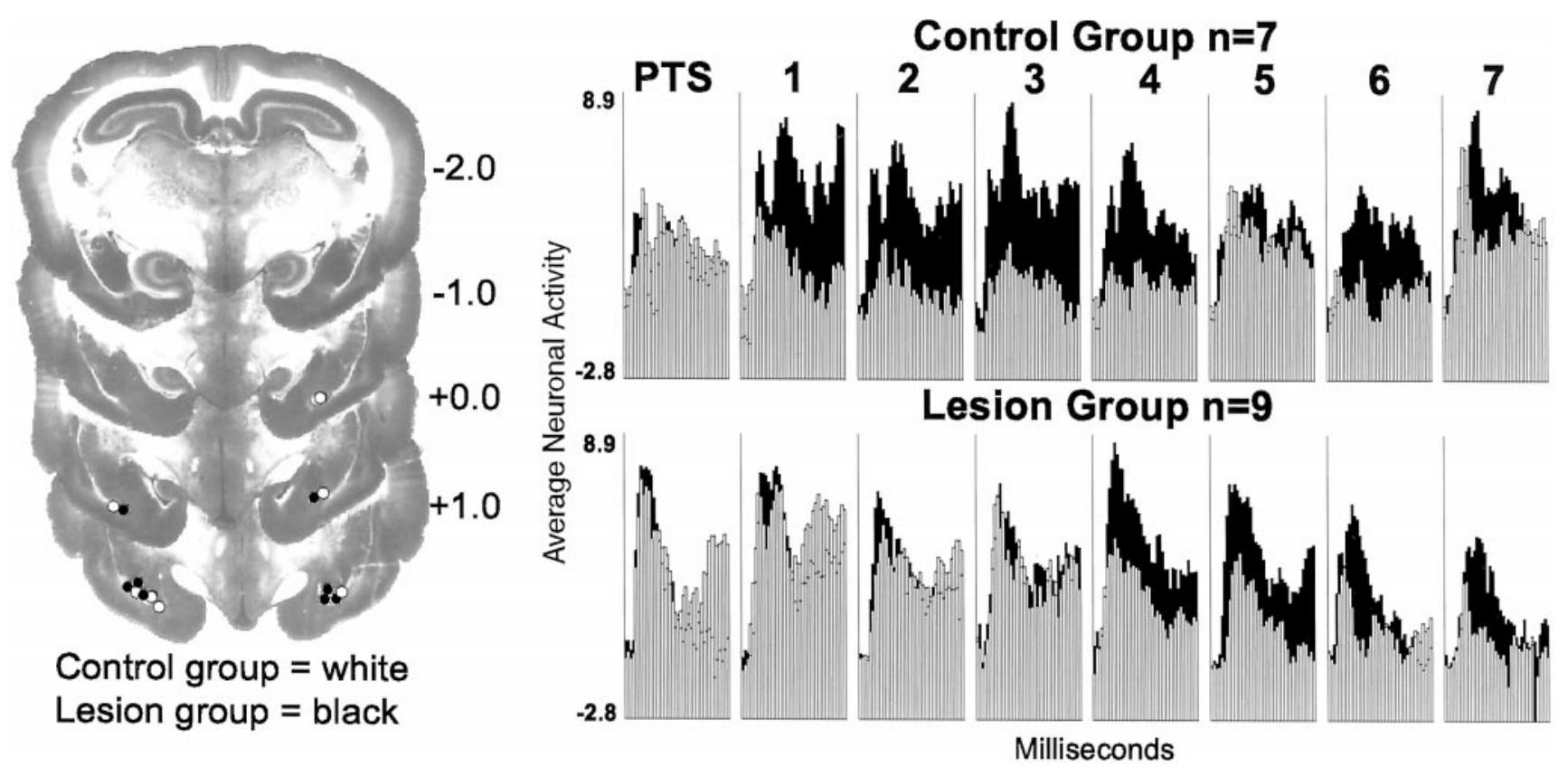

Figure 5. Electrode placements and neuronal activity recorded in the BL nucleus of the amygdala in nine rabbits with lesions and in seven controls. Other aspects of the Figure are as described in the legend of Figure 4.

cy). Simple effect tests showed that control rabbits exhibited significant discriminative TIA during training sessions 1-4, whereas rabbits with lesions exhibited no discriminative TIA during these sessions. The rabbits with lesions exhibited significant discriminative TIA only in the fifth session of training. The analysis of the firing frequency data indicated the occurrence in controls of significant discriminative TIA in training sessions 2, 3, 4 , and 6 , but no significant TIA was found in rabbits with lesions. The combined results of these analyses indicated that the lesions eliminated early TIA development in the BL nucleus and severely attenuated later TIA development in the BL nucleus. However, the single instance of discrimination during session 5 in the analysis of the integrated activity raises the possibility that latedeveloping TIA that is independent of the auditory cortex can be exhibited in the BL nucleus. No significant differences were found between lesion and control groups in the overall magnitude of tone-evoked auditory responses of neurons in the BL nucleus, the pattern of excitatory activity across sessions, or the temporal profiles of the amygdalar CS-elicited response.
Elimination of discriminative TIA in the anterior cingulate cortex in rabbits with lesions (Fig. 6) was indicated by a significant interaction of the session, stimulus, and lesion factors $(p<0.02$; $F_{(7,133)}=2.94$, integrated activity). Analysis of the simple effects showed significant discriminative TIA in controls in all training sessions except pretraining, whereas rabbits with lesions did not develop significant discriminative TIA. Analysis of the firing frequency data showed only a weak trend for the interaction of the session, stimulus, and lesion factors $\left(p<0.12 ; F_{(7,133)}=1.68\right)$. The interactions of the stimulus and lesion factors also approached significance $(p<0.10)$, as did the four-way interaction $(p<0.11)$. In conformity with the significant results of the analysis of the integrated activity, the mean neuronal response values comprising these interaction terms indicated that discriminative TIA was abolished in the anterior cingulate cortex in rabbits with lesions.

In contrast to their effects on discriminative activity, auditory cortical lesions had no effect on the overall magnitude of toneevoked neuronal responses in the anterior cingulate cortex, the 

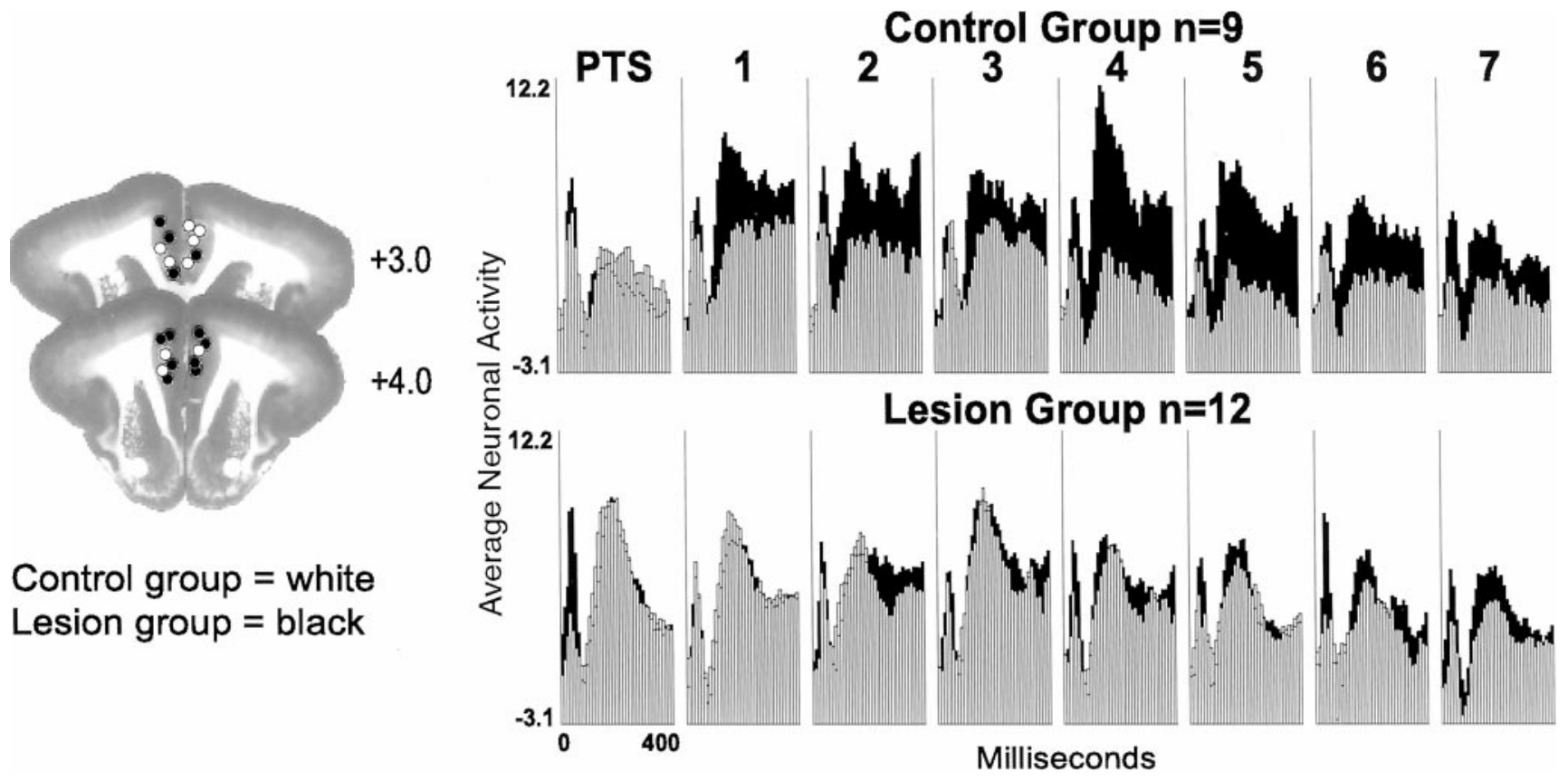

Figure 6. Electrode placements and neuronal activity recorded in the anterior cingulate cortex (Brodmann's area 24b) in 12 rabbits with lesions and in nine controls. Other aspects of the Figure are as described in the legend of Figure 4.

pattern of excitatory discharge across sessions, or the temporal profiles of the tone-elicited response. The anterior cingulate cortical records exhibited a characteristic increase in the elicited responses to both CSs during early stages of training. This pattern of excitatory neuronal activity was evident in a significant main effect of the session factor $\left(p<0.004 ; F_{(7,133)}=3.19\right)$. Analysis of the simple effects showed that tone-evoked responses recorded during the first three sessions of training were larger than those recorded during pretraining or during the last three sessions of training. The fourth session of training also had larger tone-evoked responses than the last two sessions of training. These results indicated that lesions of the auditory cortex specifically impaired the development of discriminative neuronal responses in the anterior cingulate cortex while leaving intact the training-related increase of CS-elicited firing, as well as other properties of the tone-evoked response.

\section{Abolition of early discriminative TIA and sparing of late TIA in the posterior cingulate cortex}

Lesions of the auditory cortex interfered with posterior cingulate cortical discriminative TIA in the early sessions of training but allowed discriminative TIA to occur in the later training sessions (Fig. 7). This outcome was indicated by a significant interaction of the session, stimulus, and lesion factors in the analysis of integrated activity $\left(p<0.02 ; F_{(7,119)}=3.14\right)$ and firing frequency $\left(p<0.02 ; F_{(7,119)}=2.88\right)$. Analysis of simple effects for both measures showed that controls developed significant discriminative TIA during training session 2, and this TIA persisted throughout all remaining training sessions. Rabbits with lesions exhibited significant discriminative TIA in the third, fourth, sixth, and seventh sessions in the analysis of the integrated activity and during the last four sessions of training in the analysis of the firing frequency data. The overall magnitude of auditory-evoked responses in posterior cingulate cortex was not affected by auditory cortical lesions, nor was the pattern of excitatory discharges across sessions of training or the waveform characteristics of the toneevoked response. All recordings showed a characteristic pattern of excitatory change across sessions that was not different for the controls and rabbits with lesions. These results were indicated by a significant main effect of training session in the integrated activity $\left(p<0.0001 ; F_{(7,199)}=6.34\right)$ and firing frequency data $\left(p<0.003 ; F_{(7,199)}=4.58\right)$. As found in previous studies, the analysis of the simple effects for both measures indicated that CS-elicited responses in the posterior cingulate cortex were significantly larger during the first four sessions of training than during pretraining or the last three sessions of training.

\section{Discriminative TIA in the lateral nucleus of the amygdala was} not affected by auditory cortical lesions

No significant effects of the lesions were observed in the analysis of the integrated neuronal activity of the LA amygdalar nucleus (Fig. 8). Nevertheless, the analysis indicated that the neurons in the LA nucleus of the amygdala developed discriminative TIA. The TIA increased over sessions, becoming maximal in the late training sessions. These conclusions were based on a significant interaction of the session, stimulus, and recording interval factors in the analysis of the integrated activity $\left(p<0.03 ; F_{(273,2730)}=\right.$ 1.50 ). A plot of the mean values of this interaction (data collapsed across groups) is shown in Figure 9. Because the recording interval factor participated in the interaction, the simple effect tests were conducted separately for each of the 40 poststimulus 10 msec intervals. The simple effect tests indicated that neurons of the LA nucleus of the amygdala exhibited little discriminative TIA during the first two sessions of training, whereas much more robust discriminative TIA occurred in sessions 3-7. The specific recording intervals exhibiting significant discriminative TIA are shown for each session in Table 1.

The analysis of the firing frequency data yielded a significant four-way interaction of the lesion, session, stimulus, and recording interval factors $\left(p<0.02 ; F_{(273,2330)}=1.25\right)$. The simple effect 


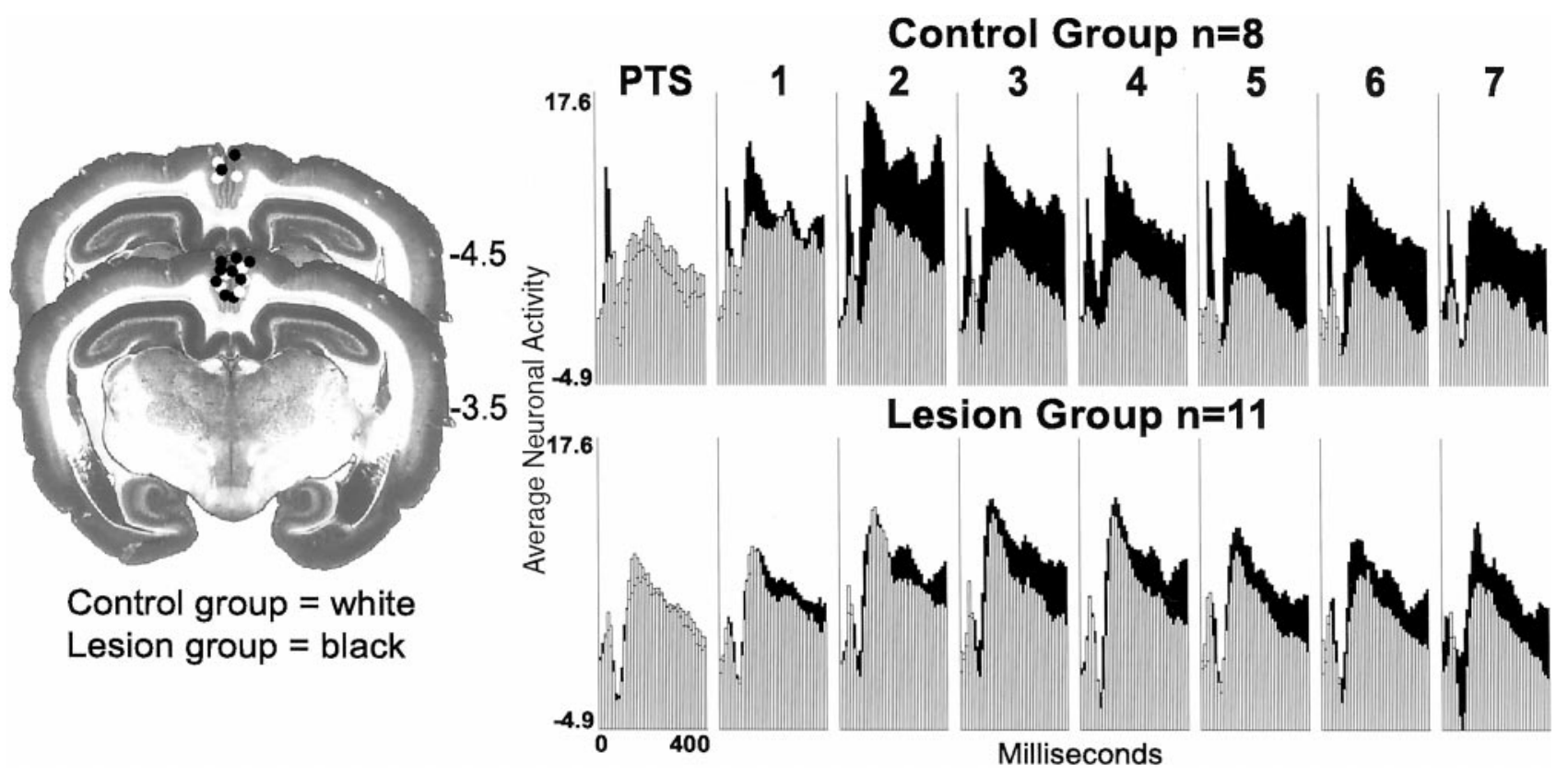

Figure 7. Electrode placements and neuronal activity recorded in the posterior cingulate cortex (Brodmann's area $29 \mathrm{c} / \mathrm{d}$ ) in 11 rabbits with lesions and in eight controls. Other aspects of the Figure are as described in the legend of Figure 4.
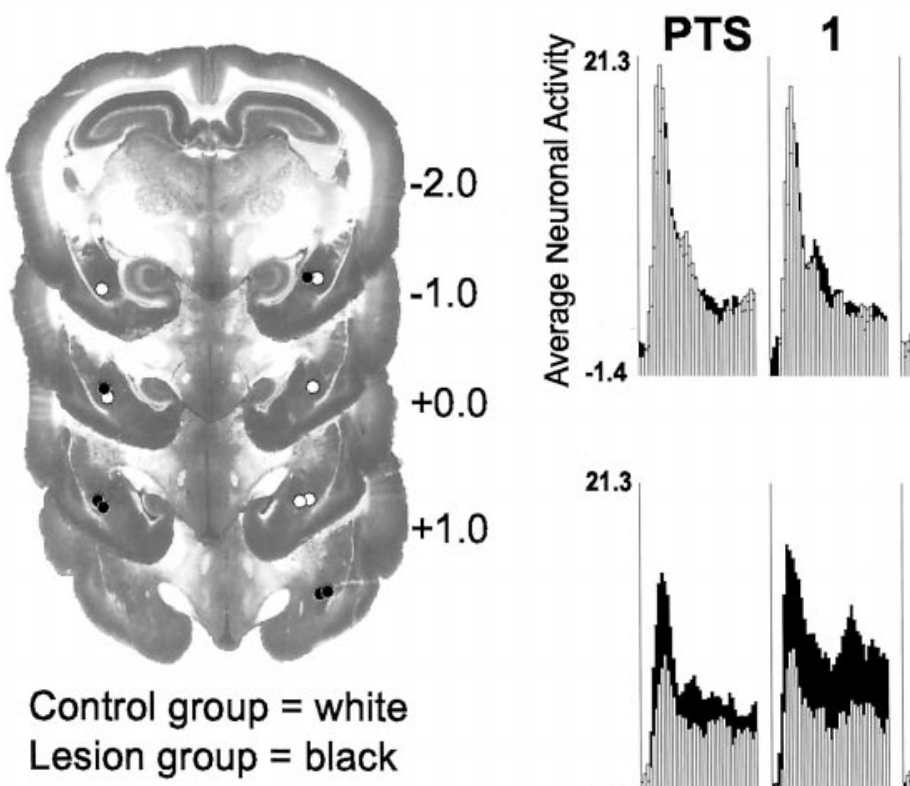

\section{Control Group $n=6$}

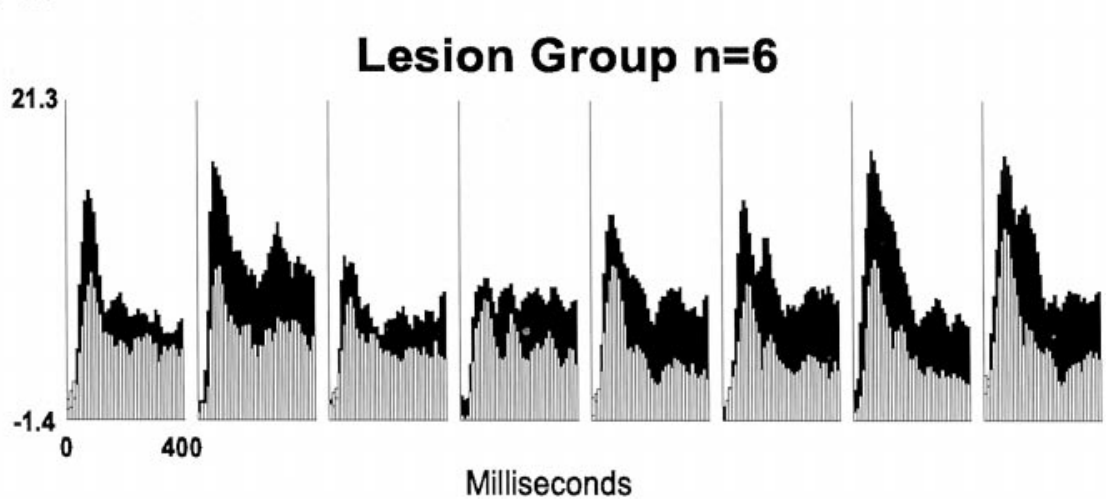

Figure 8. Electrode placements and neuronal activity recorded in the lateral nucleus of the amygdala in six rabbits with lesions and in six controls. Other aspects of the Figure are as described in the legend of Figure 4.

tests indicated that LA nuclear neurons exhibited discriminative TIA in both the lesion and control subjects. The contribution of the lesion factor to this interaction was in all likelihood a result of the fact that the number of recording intervals in which significant discrimination was found across training sessions was greater in rabbits with lesions than in controls. This result was attributable in part to the finding that during pretraining a significant neuronal "preference" for the CS+ was exhibited in the LA nucleus of rabbits with lesions, but not in controls. These effects are evident in the plots of the integrated activity (Fig. 8), which, although not identical, were highly correlated with the firing frequency data. It is likely that the apparent enhancement of discrimination in rabbits with lesions indicated by the analysis of the firing frequency data were caused by the prelearning acoustic frequency bias of the neuronal response, an accident of the rather small samples of LA amygdalar records in each group $(n=6)$. 

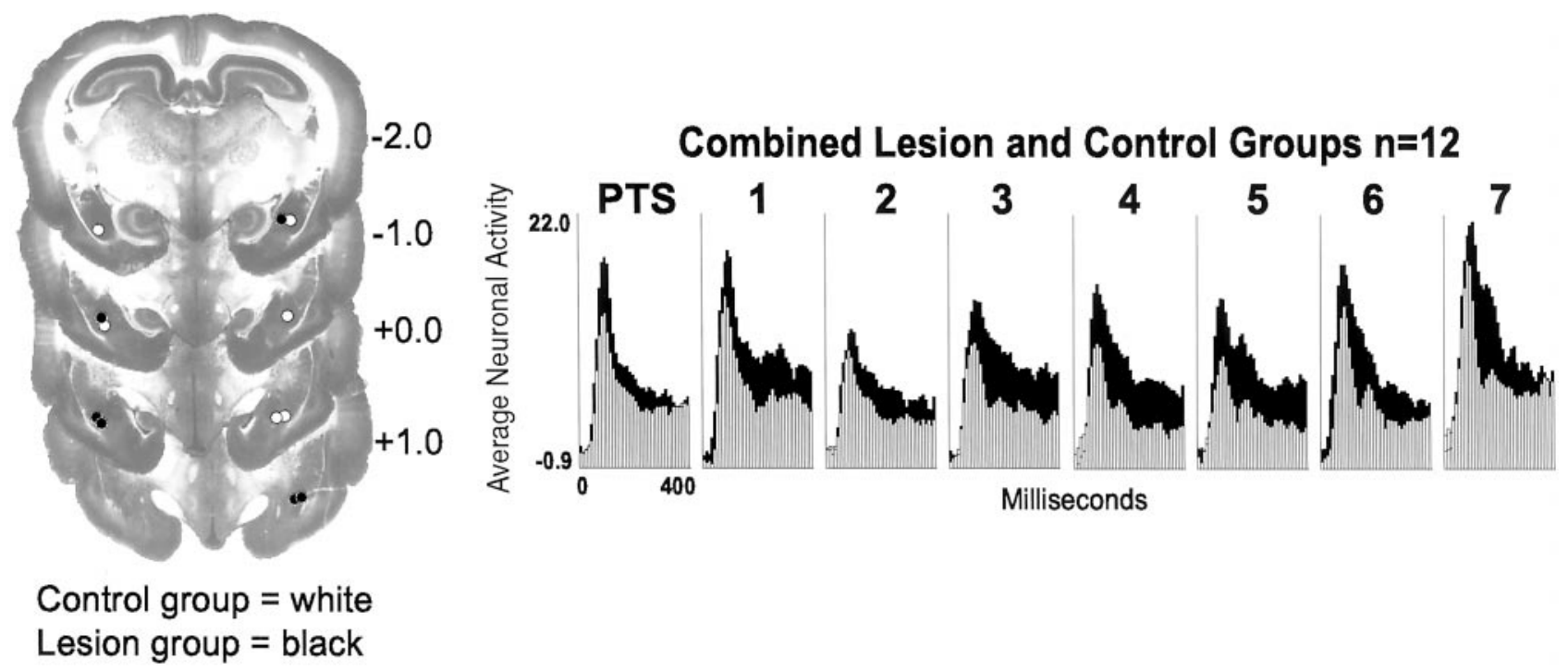

Figure 9. Neuronal activity recorded in the lateral nucleus of the amygdala. The format of the Figure is as described in the legend of Figure 4, except as follows. Because no differences were observed between the lesion and control groups, the data in Figure 9 are collapsed across the groups, yielding a total sample of 12 subjects.

\section{DISCUSSION}

This study was predicated on the recent finding that muscimolinduced inactivation of the amygdala at the outset of training blocked discriminative avoidance learning of rabbits as well as the development of discriminative TIA in the MGm (Poremba \& Gabriel, 2001). The suggestion from these results that amygdalar efferents are essential early in training for the development of discriminative TIA in the MGm raised the question of the route whereby amygdalar efferents influence the neuronal activity of the MGm. Here we tested the hypothesis that projections from the BL nucleus of the amygdala to the auditory cortex relay the critical amygdalar efferents that access the MGm via the massive corticothalamic projection system. The specific hypothesis tested was that auditory cortical lesions would block the development of discriminative TIA in the MGm. The results confirmed the hypothesis. Permanent lesions of the auditory cortex as well as temporary inactivation of the amygdala during the initial training session are manipulations that block the development of discriminative TIA in the MGm. These results encourage retention of the more general hypothesis that the flow of amygdalar efferent information to the $\mathrm{MGm}$ is essential for the development of learning-related neuronal activity in the MGm.

Conditioning-induced plasticity of CS-elicited firing of auditory cortical neurons during Pavlovian aversive conditioning in rats with amygdalar lesions (Armony et al., 1998) may seem to contradict our hypothesis, insofar as our hypothesis may foster the expectation that amygdala lesions should prevent plastic changes in the auditory cortex, as well as in the MGm. However, it should be noted that the neuronal plasticity observed by these authors was nondiscriminative and occurred at much briefer latencies (in the first $50 \mathrm{msec}$ ). It was therefore quite different from the discriminative TIA addressed by our studies. Indeed, the plasticity observed by Armony and colleagues (1998) may have occurred in the auditory cortex of the rabbits in our study and would have been observed had we obtained recordings in that area.

Our findings may be taken as supporting the view that imputes to the amygdala a general role in promoting changes relevant to behavioral learning and memory in other, nonamygdalar areas
(Cahill and McGaugh, 1998). Yet, whereas this interpretation is tenable, the present data do not decisively establish the amygdala as the promotor of plasticity in other areas of the brain. We now know not only that the integrity of the amygdala is needed for TIA in the MGm and behavioral learning, but also that the integrity of the MG nucleus is essential for BL amygdalar TIA and behavioral learning (Poremba and Gabriel, 1997b). Also, as shown here, the integrity of the auditory cortex is essential for early behavioral discrimination, as well as TIA in the BL amygdala and in the MGm. Finally, the integrity of all of these areas is necessary for the development of TIA in the cingulothalamic circuitry, which is an essential component of the learning-relevant circuitry.

These results foster the view that the MGm, the BL nucleus of the amygdala, and the auditory cortex must all be intact and in communication with one another if normative learning-relevant circuit activity is to develop in any one of these areas during training and if normative behavioral learning is to occur. Thus, it is difficult to argue from the available data that any single element of the circuitry promotes plasticity in the other regions. More generally, the results demonstrate the importance of simultaneous assessment of the interactions among multiple elements of a learning-relevant circuitry, rather than exclusive focus on a single brain region as a "critical" site of learning.

The substantial interdependence of the multiple areas of the circuitry involved in discriminative avoidance learning should not be taken to indicate that all parts of the circuitry have the same function. Indeed, the unique functional contribution of the auditory cortex is illustrated beautifully by the present finding that the lesions in this area were detrimental specifically to the discriminative aspect of learning, and only in the early sessions of training. These findings thus provide an important clue to the understanding of the specific functions of the auditory cortex in discriminative avoidance learning. The lesions did not block the ability of subjects to produce learned responses in the early training sessions (1-4), and they did not impair the ability of subjects to exhibit normative discriminative learning in later training sessions 5-7. Moreover, the early, nondiscriminative 
learning of rabbits with lesions had physiological concomitants in terms of the significantly incremented but nondiscriminative neuronal discharges of $\mathrm{BL}$ amygdalar and cingulate cortical neurons during the early training sessions. These nondiscriminative training-induced discharge increments may have contributed to the production of behavioral responses by subjects in the initial training session, as well as to responses emitted while discrimination was present but significantly impaired in training sessions $2-4$. In addition, the normative discriminative learning exhibited by rabbits with lesions in later training sessions 5-7 may have been supported in part by the late-developing neuronal discrimination in the posterior cingulate cortex, an area previously implicated in the mediation of the later stages of discriminative behavioral acquisition (Gabriel, 1993).

This study demonstrates for the first time the development of discriminative neuronal activity in the LA nucleus during discriminative avoidance conditioning in rabbits. This finding is similar to the findings of Collins and Paré (2000) who demonstrated discriminative firing in the LA nucleus during differential aversive Pavlovian conditioning of rats. Our data are also consistent with several reports of associative neuronal activity in the LA nucleus during nondiscriminative aversive Pavlovian conditioning in rats (see introductory remarks).

In the present study, the discriminative TIA in the LA nucleus was not dependent on the auditory cortex, and it developed gradually, appearing during the first session of training, increasing in magnitude throughout training, and reaching maximum magnitude in the final (seventh) session of training, when the subjects were exhibiting asymptotic behavioral discrimination. The gradual development of persistent discriminative firing served to distinguish the LA nucleus from the BL nucleus, which in this study and previous studies (Maren et al., 1991) exhibited rapid, early developing discrimination that declined in magnitude as behavioral learning approached asymptotic levels. The present findings are similar to findings recently reported by Maren (2000) of persistent associative neuronal activity of LA neurons during overtraining of Pavlovian fear conditioning in rats.

The gradual, late development of discriminative TIA in the LA nucleus was suggestive of the late-developing TIA found elsewhere in the learning-relevant circuitry (Gabriel, 1993). Thus, the present data suggest the inclusion of an amygdalar component in the anatomical definition of both the early and latediscriminating neural circuits. Specific cooperation between the $\mathrm{BL}$ nucleus and anterior cingulate cortex is suggested by the presence of direct axonal connections (Macchi et al., 1978; Amaral and Price, 1984; Sripanidkulchai et al., 1984), the exhibition of early discriminative TIA in both areas (Gabriel, 1993), and common involvement of both areas in the early stages of behavioral learning (Gabriel, 1993). The LA nucleus of the amygdala exhibits maximal discriminative TIA in late stages of acquisition, in common with neurons in certain components of the posterior cingulate cortex and the limbic (anterior and medial dorsal) thalamic nuclei, suggesting the possibility of cooperation among these areas in mediating late-developing behavioral discrimination. Although lesion studies demonstrating a direct involvement of the LA nucleus in the late stages of discriminative avoidance learning have not yet been carried out, evidence supportive of this idea has been reported in studies of Pavlovian fear conditioning (Maren, 2000; Wallace and Rosen, 1999). These results thus confirm and extend the original discovery (for review, see Gabriel, 1993) of distinct brain circuitries for early and later stages of discriminative conditioning.
The notion that several widely distributed areas, including the LA nucleus, may cooperate to produce late discriminative TIA does not acknowledge any one of the areas as a primary site of the late TIA. Just as for the regions that exhibit early discrimination, it is likely that our "interdependence hypothesis" is valid for all of the late-discriminating areas. That is, all of these areas must be intact and interconnected if late discrimination is to develop in any one of them. Yet, although this hypothesis has received substantial empirical support (reviewed above) in relation to the early discriminating areas, its relevance to the late discriminating areas has not been tested. Moreover, our demonstrations that the late-developing LA amygdalar activity is independent of the auditory cortex and of associative plasticity in the MGm are compatible with an alternative hypothesis (Maren and Fanselow, 1996; Fanselow and LeDoux, 1999) that the LA nucleus is a primary site for coding of the CS-US association.

\section{REFERENCES}

Amaral DG, Price JL (1984) Amygdalo-cortical projections in the monkey (Macaca fascicularis). J Comp Neurol 230:465-496.

Andersen RA, Knight PL, Merzenich MM (1980) The thalamocortical and corticothalamic connections of AI, AII, and the anterior auditory field in the cat: evidence for two largely segregated systems of connections. J Comp Neurol 194:663-701.

Armony JL, Quirk GJ, LeDoux JE (1998) Differential effects of amygdala lesions on early and late plastic components of auditory cortex spike trains during fear conditioning. J Neurosci 18:2592-2601.

Ben-Ari Y, Le Gal La Salle G (1974) Lateral amygdala unit activity. II. Habituating and non-habituating neurons. Electroencephalogr Clin Neurophysiol 37:463-472.

Brogden WJ, Culler FA (1936) A device for the conditioning of small animals. Science 83:269.

Buchwald WJ, Holstein SB, Weber DS (1973) Multiple-unit recording: technique, interpretation, and experimental applications. In: Bioelectric recording techniques. A. Cellular processes and brain potentials (Thomson RF, Patterson MM, eds), pp 202-242. New York: Academic.

Cahill L, McGaugh JL (1998) Mechanisms of emotional arousal and lasting declarative memory. Trends Neurosci 21:294-299.

Collins DR, Paré D (2000) Differential fear conditioning induced reciprocal changes in the sensory responses of lateral amygdala neurons to the CS+ and CS - . Learn Mem 7:97-103.

DeVenecia RK, Smelser CB, McMullen NT (1998) Parvalbumin is expressed in a reciprocal circuit linking the medial geniculate body and auditory neocortex in the rabbit. J Comp Neurol 400:349-362.

Diamond IT, Jones EG, Powell TPS (1969) The projection of the auditory cortex upon the diencephalon and brainstem in the cat. Brain Res 15:305-340.

Donovick PJ (1974) A metachromatic stain for neural tissue. Stain Technol 49:49-51.

Edeline JM, Weinberger NM (1992) Associative retuning in the thalamic source of input to the amygdala and auditory cortex: receptive field plasticity in the medial division of the medial geniculate body. Behav Neurosci 106:81-105.

Fanselow MS, Kim JJ (1994) Acquisition of contextual Pavlovian fear conditioning is blocked by application of NMDA receptor antagonist D,L-2-amino-5-phosphonovaleric acid to the basolateral amygdala. Behav Neurosci 108:210-212.

Fanselow MS, LeDoux JE (1999) Why we think plasticity underlying Pavlovian fear conditioning occurs in the basolateral amygdala. Neuron 23:229-232.

Fox CA, Eichman J (1959) A rapid method for locating intracerebral electrode tracks. Stain Technol 34:39-42.

Gabriel M (1993) Discriminative avoidance learning: a model system. In: Neurobiology of the cingulate cortex and limbic thalamus: a comprehensive handbook (Vogt BA, Gabriel M, eds), pp 478-523. Boston: Birkhauser.

Gabriel M, Saltwick SE, Miller J (1975) Conditioning and reversal of short-latency multiple-unit responses in the rabbit medial geniculate nucleus. Science 189:1108-1109.

Gabriel M, Miller J, Saltwick SE (1976) Multiple unit activity of the rabbit medial geniculate nucleus in conditioning, extinction and reversal. Physiol Psychol 4:124-134.

Gabriel M, Lambert RW, Foster K, Orona E, Sparenborg S, Majorca RR (1983) Anterior thalamic lesions and neuronal activity in cingulate and retrosplenial cortices during discriminative avoidance behavior in rabbits. Behav Neurosci 97:675-696.

Gentile CG, Jarrell TW, Teich A, McCabe PM, Schneiderman N (1986) The role of the amygdaloid central nucleus in the retention of differ- 
ential Pavlovian conditioning of bradycardia in rabbits. Behav Brain Res 20:263-273.

Girgis M, Shih-Chang W (1981) A new stereotaxic atlas of the rabbit brain. St. Louis: Warren H. Green.

Hennevin E, Maho C, Hars B (1998) Neuronal plasticity induced by fear conditioning is expressed during paradoxical sleep: evidence from simultaneous recordings in the lateral amygdala and the medial geniculate in rats. Behav Neurosci 112:839-862.

Hitchcock JM, Davis M (1987) Fear potentiated startle using an auditory conditioned stimulus: effect of lesions of the amygdala. Physiol Behav 39:403-408.

Hyunh H, Feldt LS (1976) Estimation of the box correction for degrees of freedom from sample data in randomized-block and split-plot designs. J Educ Stat 1:69-82.

Jarrell TW, Gentile CG, McCabe PM, Schneiderman N (1986a) The role of the medial geniculate nucleus in differential Pavlovian conditioning of bradycardia in rabbits. Brain Res 374:126-136.

Jarrell TW, Ramanski LM, Gentile CG, McCabe PM, Schneiderman N (1986b) Ibotenic acid lesions in the medial geniculate region prevent the acquisition of differential Pavlovian conditioning of bradycardia to acoustic stimuli in rabbits. Brain Res 382:199-203.

Kapp BS, Frysinger RC, Gallagher M, Hasleton JR (1979) Amygdala central nucleus lesions: effect on heart rate conditioning in the rabbit. Physiol Behav 23:1107-1117.

LeDoux JE (1993) Emotional memory systems in the brain. Behav Brain Res 58:69-79.

LeDoux JE (1995) Emotion: clues from the brain. Annu Rev Psychol 46:209-235.

LeDoux JE, Ruggiero DA, Reis DJ (1985) Projections to the subcortical forebrain from anatomically defined regions of the medial geniculate body in the rat. J Comp Neurol 242:182-213.

LeDoux JE, Iwata J, Perl D, Reis DJ (1986) Disruption of auditory but not visual learning by destruction of intrinsic neurons in the medial geniculate body of the rat. Brain Res 371:395-399.

LeDoux JE, Cicchetti P, Xagoraris A, Romanski LM (1990) The lateral amygdaloid nucleus: sensory interface of the amygdala in fear conditioning. J Neurosci 10:1062-1069.

Lennartz RC, Weinberger NM (1992) Frequency-specific receptive field plasticity in the medial geniculate body induced by Pavlovian fear conditioning is expressed in the anesthetized brain. Behav Neurosci 106:484-497.

Macchi G, Bentivoglio P, Rossini P, Tempesta E (1978) The basolateral amygdaloid projections to the neocortex in the cat. Neurosci Lett 9:347-351.

Maren S (2000)Auditory fear conditioning increases CS elicited spike firing in lateral amygdala neurons even after extensive overtraining. Eur J Neurosci 12:4047-4054.

Maren S, Fanselow MS (1996) The amygdala and fear conditioning: has the nut been cracked? Neuron 16:237-256.

Maren S, Poremba A, Gabriel M (1991) Basolateral amygdaloid multiunit neuronal correlates of discriminative avoidance learning in rabbits. Brain Res 549:311-316.

McCabe PM, McEchron MD, Green EJ, Schneiderman N (1993) Electrolytic and ibotenic acid lesions of the medial subnucleus of the medial geniculate prevent the acquisition of classically conditioned heart rate to a single acoustic stimulus in rabbits. Brain Res 619:291-298.

McEchron MD, McCabe PM, Green EJ, Llabre MM, Schneiderman N (1995) Simultaneous single unit recording in the medial nucleus of the medial geniculate and amygdaloid central nucleus throughout habituation, acquisition and extinction of the rabbit's classically conditioned heart rate. Brain Res 682:157-166.

McEchron MD, Green EJ, Winters RW, Nolen TG, Schneiderman N, McCabe PM (1996) Changes of synaptic efficacy in the medial geniculate nucleus as a result of auditory classical conditioning. J Neurosci 16:1273-1283.

McMullen NT, DeVenecia RK (1993) Thalamocortical patches in auditory neocortex. Brain Res 620:317-322.

McMullen NT, Smelser CB, DeVenecia RK (1994) A quantitative analysis of parvalbumin neurons in rabbit auditory neocortex. J Comp Neurol 349:493-511.

Muramoto K, Ono T, Nishijo H, Fukuda M (1993) Rat amygdaloid neuronal responses during auditory discrimination. Neuroscience 52:621-636.

Paré D, Collins DR (2000) Neuronal correlates of fear in the lateral amygdala: multiple extracellular recordings in conscious cats. J Neurosci 20:2701-2710.

Payne J, Hanlon J, Cantey J, Mungnirun K, Duvel A, Smith D, Gimbel K, Nelson M, Gabriel M (1999) High-resolution digital rabbit brain atlases for behavioral neuroscience. Soc Neurosci Abstr 25:877.

Pontes C, Reis FF, Sousa-Pinto A (1975) The auditory cortical projections onto the medial geniculate body in the cat. An experimental anatomical study with silver and autoradiographic methods. Brain Res 91:43-63.

Poremba A, Gabriel M (1997a) Amygdalar lesions block discriminative avoidance learning and cingulothalamic training induced neuronal plasticity in rabbits. J Neurosci 17:5237-5244.

Poremba A, Gabriel M (1997b) Medial geniculate lesions block amygdalar and cingulothalamic learning related neuronal activity. J Neurosci 17:8645-8655.

Poremba A, Gabriel M (1999) Amygdala neurons mediate acquisition but not maintenance of instrumental avoidance behavior in rabbits. J Neurosci 19:9635-9641.

Poremba A, Gabriel M (2001) The amygdala enables the development of medial geniculate training-induced neuronal plasticity during discriminative avoidance learning in rabbits. J Neurosci 21:260-268.

Quirk GJ, Repa C, LeDoux JE (1995) Fear conditioning enhances shortlatency auditory responses of lateral amygdala neurons: parallel recordings in the freely behaving rat. Neuron 15:1029-1039.

Rescorla RA (1967) Pavlovian conditioning and its proper control procedures. Psychol Rev 74:71-80.

Sripanidkulchai K, Sripanidkulchai B, Wyss JM (1984) The cortical projection of the basolateral amygdaloid nucleus in the rat: a retrograde flourescent dye study. J Comp Neurol 229:419-431.

Wallace KJ, Rosen JB (1999) Lesions of the lateral nucleus of the amygdala decrease freezing in rats to contextual fear conditioning and to a predator odor. Soc Neurosci Abstr 25:1618.

Winer BJ (1962) Statistical principles in experimental design, pp. 298374. New York: McGraw-Hill. 